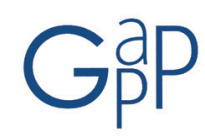

GESTIÓN Y ANÁLISIS DE POLÍTICAS PÚBLICAS, Nueva Época, nº 14 julio-diciembre 2015 ISSN: 1989-8991

DOI: http://dx.doi.org/10.24965/gapp.voi14.10288

\title{
Las conferencias sectoriales (2001-2012): Dinámica de funcionamiento y valores y percepciones de los agentes políticos y técnicos
}

\author{
Alberto de la Peña Varona \\ Universidad del País Vasco \\ alberto.delapena@ehu.eus \\ Arantxa Elizondo Lopetegi \\ Universidad del País Vasco \\ arantxa.elizondo@ehu.eus \\ Francisco Juaristi Larrinaga \\ Universidad del País Vasco \\ patxi.juaristi@ehu.es \\ Juan Luis Mokoroa Arizkorreta \\ Universidad del País Vasco \\ juanluis.mokoroa@ehu.eus \\ Jaione Mondragón Ruiz de Lezana \\ Universidad del País Vasco \\ jaione.mondragon@ehu.eus
}

\section{Resumen}

La organización territorial establecida en España desde 1978 se ubica en un punto intermedio entre los modelos unitarios y federales. En este marco institucional, la coordinación de las políticas sectoriales se ha canalizado a través de organismos intergubernamentales como las Conferencias Sectoriales, que pretenden integrar a las Comunidades Autónomas en los procesos de toma de decisión del Estado. De la misma manera, estas Conferencias son canales para establecer una coordinación horizontal entre las Comunidades Autónomas en un contexto como el español, donde apenas han tenido desarrollo suficiente otras herramientas diseñadas especificamente a este fin.

En este artículo se presentan las principales conclusiones de un proyecto de investigación financiado por el Instituto Nacional de Administración Pública (INAP) en 2013 Este proyecto se orienta al análisis del funcionamiento, la dinámica y los resultados del trabajo de las Conferencias Sectoriales, así como a su papel como instrumentos de gobierno compartido. Para ello, se ha realizado un análisis empírico que, además del estudio formal de estos organismos, presta atención a elementos como el factor humano, el liderazgo, la ideología o la propia naturaleza de los temas tratados.

\section{Palabras clave}

Conferencias Sectoriales, Relaciones Intergubernamentales, Gobierno Multinivel, Organización Territorial del Estado, Estado Autonómico, Estado Federal, Cooperación administrativa.

\section{The Sectoral Conferences (2001-2012): Working dynamics and the values and perceptions of the political and technical agents}

\section{Abstract}

The territorial organization established in Spain since 1978 is located at an intermediate point between unitary and federal models. In this institutional framework, coordination of sectoral policies has been channeled through intergovernmental organizations such as the Sectorial Conferences, which aim to integrate the Autonomous Regions in the decision making processes of the State. Similarly, these conferences are channels to establish a horizontal coordination between Autonomous Regions in a context such as Spanish, where they have just had enough other development tools designed specifically for this purpose.

In this article are presented the main findings of a research project funded by the National Institute of Public Administration (INAP) in 2013. This project aims to analyze the functioning, dynamics and the results of work of the Sectorial Conferences, as well as their role as instruments of shared governance. To do this, there has been an empirical analysis that besides the formal study of these organisms, pay attention to elements such as the human factor, leadership, ideology or the nature of the issues.

Keywords

Sectoral Conferences, Intergovernmental Relations, Multilevel Governance, Territorial Organization of the State, Autonomy State, Federal State, Administrative cooperation. 
ÍNDICE: RESUMEN Y PALABRAS CLAVE. 1. INTRODUCCIÓN. 2. DISEÑO METODOLÓGICO-TÉCNICO DE LA INVESTIGACIÓN. 3. LAS CONFERENCIAS SECTORIALES EN ESPAÑA. 3.1. Las Conferencias Sectoriales en el contexto del modelo territorial del Estado. 3.2. Origen y configuración. 3.3. Trayectoria de las Conferencias Sectoriales. 4. DINAMICA DE FUNCIONAMIENTO DE LAS CONFERENCIAS SECTORIALES. 4.1. Naturaleza jurídica. 4.2. Funciones. 4.3. Composición y asistencia. 4.4. Convocatoria y orden del día. 4.5. Órganos de preparación y apoyo. 4.6. Toma de decisiones. 5. EL FACTOR HUMANO EN EL FUNCIONAMIENTO DE LAS CONFERENCIAS SECTORIALES. 5.1. Rasgos ideológicos: concepciones sobre la organización territorial y el alineamiento partidista. 5.2. Liderazgo personal: habilidades sociales y perfil formativo. 6. CONCLUSIONES. 7. REFERENCIAS BIBLIOGRÁFICAS Y DOCUMENTALES. ANEXO I. FICHA TÉCNICA DE LAS ENTREVISTAS EN PROFUNDIDAD.

\section{INTRODUCCIÓN}

Durante las últimas décadas venimos observando que la forma de gobernar en los diferentes contextos políticos avanza inexorablemente hacia un sistema de gobierno en el que la interdependencia, la colaboración y la cooperación entre los elementos que los integran se hacen imprescindibles en los procesos de toma de decisiones y gestión pública.

Actualmente vivimos un proceso de transformación y de innovación en muchos aspectos relativos a nuestras administraciones públicas; no pueden quedar fuera de este proceso la revisión de los mecanismos de relaciones intergubernamentales, más aun si consideramos que organismos como las Conferencias Sectoriales, definidas como las manifestaciones organizadas de la cooperación, juegan un papel cada vez más decisivo como foros de debate de las reformas que se adoptan para atender la actual coyuntura económica. Hay que añadir a esto que quienes se han acercado al estudio de estos órganos han puesto en evidencia una serie de aspectos sobre su organización y actividad que plantean, cuando menos, algunos interrogantes sobre su funcionamiento real.

Este artículo tiene como objeto de estudio los mecanismos formales de relaciones intergubernamentales en el Estado de las Autonomías, más concretamente las que se llevan a cabo a través de las Conferencias Sectoriales. Nos interesan los aspectos estructurales pero fundamentalmente el funcionamiento, la dinámica y los resultados de estas Conferencias, así como el papel que juegan como órganos de cogobierno en el Estado. El estudio aquí presentado recoge parte de una investigación financiada por el Instituto Nacional de Administración Pública (INAP) en el año 2013.

Con los datos y la información recopilada, pretendemos avanzar en el diagnóstico de las Conferencias Sectoriales, profundizando sobre diferentes cuestiones que explican su funcionamiento real.

\section{DISEÑO METODOLÓGICO-TÉCNICO DE LA INVESTIGACIÓN}

Hemos optado por centrar nuestro objeto de estudio entre los años 2001-2012 porque es el período en que se registra un mayor número de reuniones de las Conferencias Sectoriales. Nuestra investigación se basa en el análisis en profundidad de tres conferencias: las Conferencias Sectoriales de Educación, Salud y Medio Ambiente. Esto se debe a tres motivos: en primer lugar, las tres han sido creadas entre los años 1986 y 1989 , momento en el que hubo un crecimiento importante en el número de conferencias; en segundo lugar, las tres han tenido una actividad regular desde el año 2001 al 2012; y en tercer lugar, las tres cuentan con un notable peso específico (en estas materias se concentra una parte muy sustancial del gasto público) y una importante proyección territorial de las políticas del sector, pudiendo darse confrontación entre intereses territoriales e ideológicos.

Para conocer el funcionamiento, la dinámica y los resultados de estas tres Conferencias hemos combinado técnicas cualitativas y cuantitativas. Una decisión metodológica clave tiene que ver con los actores analizados. En este sentido, debemos señalar que, además de entrevistar al personal técnico que trabaja en las Conferencias Sectoriales, se ha recabado la opinión de Consejeros y Consejeras, Directores y Directoras y Viceconsejeros y Viceconsejeras que representan a tres Comunidades Autónomas que entre los años 2001 y el 2012 han tomado parte en estas tres Conferencias Sectoriales: Comunidad Autónoma de Cataluña, Comunidad Autónoma de Madrid y Comunidad Autónoma del País Vasco. La elección de estos tres casos se debe a que son comunidades de perfil político diferenciado (buscamos el contraste entre gobiernos nacionalistas y no nacionalistas, y entre gobiernos autonómicos de izquierda y de derecha) y con sistemas de financiación también distinto. Concretamente han sido 16 las entrevistas en profundidad enfocadas y semiestructuradas realizadas: cuatro entre personal técnico que trabaja en la coordinación y/o organización de las Conferencias Sectoriales, 10 entre Consejeros y Consejeras autonómicas y dos entre Viceconsejeros y Directores generales que acudían en lugar de los Consejeros y Consejeras 
a las Conferencias Sectoriales y participaban en sus correspondientes comisiones generales. Estas entrevistas se realizaron fundamentalmente en los lugares de trabajo de las personas entrevistadas entre el 22 de abril del 2014 y el 12 de octubre del 2014.

Además de las entrevistas en profundidad, se ha realizado un análisis de contenido de los órdenes del día y las actas de las reuniones de las tres Conferencias desde el año 2001 al 2012. Para ello nos hemos basado en las siguientes categorías:

- Fecha de celebración: entre el 2001 y el 2012 se ha registrado el día, mes y año en el que se realizó la conferencia.

- Duración: tiempo que duró la conferencia.

- $\quad$ N. ${ }^{\circ}$ de puntos del orden del día: se ha cuantificado el número de puntos del orden del día.

- $\quad$ N. ${ }^{\circ}$ de páginas: se ha cuantificado el número de páginas del acta (como indicador de la extensión y detalle de las sesiones de la conferencia).

- Lugar de celebración de la conferencia: se ha codificado la ciudad en la que se celebrado la conferencia.

- Presidencia de la conferencia: se ha analizado quién presidía la conferencia.

- $\quad$ Rango de las personas que han acudido: se ha codificado si las personas que han acudido por cada Comunidad Autónoma tenían rango de consejero, Viceconsejero, secretario, subsecretario, director o coordinador general.

Se ha llevado a cabo también el análisis de la normativa (leyes y reglamentos) sobre las Conferencias Sectoriales y, por último, hemos analizado los Informes sobre la actividad de las Conferencias Sectoriales que elabora y recoge la Dirección General de Coordinación de Competencias con las Comunidades Autónomas y las Entidades Locales del Ministerio de Hacienda y Administraciones Públicas (MINHAP).

\section{LAS CONFERENCIAS SECTORIALES EN ESPAÑA}

\subsection{Las Conferencias Sectoriales en el contexto del modelo territorial del Estado}

El concepto de Relaciones Intergubernamentales, según Wright, hace mención a dos dimensiones: la primera alude a las conexiones que se establecen entre distintos niveles territoriales de gobierno y la segunda tiene que ver con las relaciones entre entes gubernamentales del mismo nivel territorial (Wright, 1997: 8-9). En este estudio nos hemos centrado en el examen de ciertas instituciones de colaboración vertical y multilateral, como son las Conferencias Sectoriales, puesto que son una de las vías más extensamente utilizadas de cogobierno o colaboración entre administraciones (Colino y Parrado, 2009: 25), a pesar de que muestren una serie de características que relativizan su potencial como verdaderos instrumentos para la canalización de la cooperación intergubernamental (Ruiz González, 2013:11), (Arbós Marín, Colino, García Morales y Parrado, 2009: 138 y ss) y (Colino, 2012: $223-227$ y 2014: 841-855).

En cualquier caso, un análisis como éste nos ha de llevar forzosamente a consideraciones más generales sobre el planteamiento y posterior funcionamiento del Estado de las Autonomías en el que se insertan las Conferencias Sectoriales. Desde la literatura especializada se han citado algunos obstáculos que van más allá de la arquitectura institucional de éste y que hunden sus raíces en el propio proceso histórico. Por ejemplo, el fuerte peso en la cultura política de la rivalidad Estado-Comunidades Autónomas, una cultura administrativa reacia a "perder" competencias y la insuficiencia manifiesta de los mecanismos tradicionales del modelo burocrático para dar respuesta a las necesidades de un contexto administrativo descentralizado y plural (Mendoza, 1990:266-267), (Moreno, 1997: 102-105). Además, podríamos hablar de las reticencias del nacionalismo de las comunidades históricas que ha tendido a ver con poco entusiasmo la cooperación con otros actores autonómicos del Estado, especialmente a partir del proceso de igualación competencial iniciado en 1992 (Aja, 2014: 56). Asimismo, podríamos citar también una ausencia histórica de un cierto federalismo cooperativo (Peña Díez, 2010: 68-69; Tajadura, 2010: 175) presente en otras latitudes y que, entre otras cosas, habría incapacitado a los partidos estatales para superar las claves de rivalidad partidista en los órganos destinados a dar desarrollo a la cooperación entre territorios. En el fondo toda esta problemática podría venir determinada por las razones profundas del surgimiento del Estado de las Autonomías: el proceso descentralizador en España -independientemente de sus logros- parece estar marcado más para retener a nacionalidades históricas dentro del Estado (Linz 1997: 35-39) que para incluir a las entidades territoriales en las decisiones comunes sobre la base de un gobierno compartido más propio de federalismos unificadores (bringing together federalism) (Maíz et al. 2002: 388). 
En este contexto, encontramos en el modelo territorial español asimetrías de facto y de iure determinadas por factores diversos y reconducibles a las esferas fiscal, económica, social y política (Agranoff, 2006: 4-5) ${ }^{1}$ A pesar de que, al menos en lo económico, esta variabilidad sea también un hecho en otros casos de modelos descentralizados, en el caso español ha supuesto uno de los obstáculos que ha dificultado la consecución de un modelo de financiación autonómica consensuado que equipare la disponibilidad de recursos por habitante, lo que ha tratado de compensarse mediante los mecanismos de solidaridad interterritorial con desigual fortuna (Pérez García, 2002: 23-29; Lagos et al. 2010: 120, Vega García, 2014: 246-247). En un plano más vinculado a la arquitectura institucional del nivel central, uno de los aspectos que condicionan la cooperación interterritorial es la ausencia de instituciones clave del federalismo. El ejemplo más comúnmente citado cuando tal aspecto es analizado es el insuficiente carácter territorial del Senado que sólo parcialmente puede considerarse una cámara de representación de las Comunidades Autónomas. Hasta la fecha, su posible reforma ha sido un debate recurrente pero todavía no se ha plasmado en medidas concretas, quedando relegado su papel al de mera cámara auxiliar del Congreso de los Diputados, subordinada en el proceso legislativo y sometida a las relaciones de competencia interpartidista que presiden aquélla. Como señalan entre otros Romero (2005: 65-66) y Moreno (1997: 157), ello ha imposibilitado la creación de un espacio de codecisión entre las diferentes comunidades, especialmente necesario en aquéllas políticas sectoriales -como las de educación, medioambiente o salud- cuya competencia ejecutiva recae en las autonomías de manera prácticamente exclusiva por mandato constitucional. Teniendo en cuenta este diseño institucional, no es extraño que en algunos trabajos comparativos como el de Marks et al. (2008: 273) aparezca el caso español como un modelo territorial lejano aún al federalismo: si bien en términos de autogobierno el caso español equipara sus Comunidades Autónomas a otras entidades territoriales propias de modelos federales, la otra cara de la descentralización -la del gobierno compartido- permanece en un nivel de desarrollo similar al de los casos comúnmente considerados como ejemplo de estados centralizados. En otros términos, el estado autonómico se caracterizaría por conceder notables competencias a las entidades territoriales sin posibilitar la concurrencia de éstas a la formación de las decisiones comunes.

Planteado este contexto en el que se sitúan las Conferencias Sectoriales, es probable que se manifiesten todas las reticencias de los diferentes actores políticos hacia un modelo territorial que aún hoy cuenta con una precaria base ideológica-política. En ese sentido, partimos de la base de que existe un relativamente reducido número de actores que apuestan por el federalismo cooperativo y un entramado institucional que no ha favorecido la reversión de esta tendencia e incluso sigue manteniendo una rivalidad Estado-Comunidades Autónomas. Creemos que ello tiene que ejercer alguna influencia necesariamente en organismos como las Conferencias Sectoriales, un tipo de institución.

Planteado este contexto en el que se sitúan las Conferencias Sectoriales, es probable que se manifiesten todas las reticencias de los diferentes actores políticos hacia un modelo territorial que aún hoy cuenta con una precaria base ideológica-política. En ese sentido, partimos de la base de que existe un relativamente reducido número de actores que apuestan por el federalismo cooperativo y un entramado institucional que no ha favorecido la reversión de esta tendencia e incluso sigue manteniendo una rivalidad Estado-Comunidades Autónomas. Creemos que ello tiene que ejercer alguna influencia necesariamente en organismos como las Conferencias Sectoriales, un tipo de institución planteada para facilitar el ámbito del gobierno compartido, o la participación de las entidades territoriales en las decisiones comunes del Estado.

\subsection{Origen y configuración}

A comienzos de la década de los 80 se pusieron en marcha las primeras Conferencias Sectoriales a instancia de los diferentes actores territoriales. ${ }^{2}$ La Ley 12/83 de 14 de octubre del Proceso Autonómico y posteriormente los Acuerdos Autonómicos de 1992, supusieron un reconocimiento a la figura de las Conferencias Sectoriales, reconociéndolas institucionalmente como el instrumento fundamental de desarrollo de una actuación cooperativa entre Estado y Comunidades Autónomas. Los citados acuerdos contemplaban respecto al funcionamiento de las Conferencias Sectoriales, el principio de consentimiento de las partes, debiéndose adoptar los acuerdos por unanimidad, como regla general, si bien es cierto que este principio podría ser sustituido en ocasiones por la regla

1 Desde otro punto de vista, algunos autores han analizado cómo la diversidad geográfica, demográfica, socioeconómica y política de las CCAA ha afectado a su relación con el nivel local (Cicuéndez y Ramos 2011).

2 Durante la década de los años ochenta hasta los Acuerdos Autonómicos de 1992 se crearon las siguientes Conferencias Sectoriales: 1981: Consejo de Política Fiscal y Financiera de las Comunidades Autónomas; (L.O.8/1980 (art. 3.1)1983: Conferencia Sectorial de Agricultura y Desarrollo Rural; 1984: Conferencia Sectorial de Turismo; 1985: Conferencia Sectorial del Plan Nacional sobre Drogas; 1986: Conferencia Sectorial de Educación (L.0.8/1985: art. 28); 1987: Conferencia Sectorial de Consumo (Texto refundido, R.D. Legislativo 1/2007: art. 40 y 41); 1987: Consejo Interterritorial del Sistema Nacional de Salud (Ley 16/2003: art. 69.1); 1987: Conferencia Sectorial de Vivienda Urbanismo y Suelo; 1988:Conferencia Nacional de Transportes (Ley 16/1987: art. 9.1); 1988: Conferencia Sectorial de Medio Ambiente; 1988:Conferencia Sectorial para Asuntos relacionados con las Comunidades Europeas (desde 2010 ha pasado a denominarse: Conferencia Sectorial para Asuntos relacionados con la Unión Europea). 
de la mayoría. Así mismo, es significativa la importancia que se le concedía a la asistencia y participación en dichas conferencias, condicionando a esta cuestión los resultados de las mismas. De igual forma, se consideraba necesario introducir mecanismos de cooperación en el seno de cada conferencia que posibilitaran una toma de decisiones por las partes propiciando la participación de las Comunidades Autónomas en la articulación de políticas generales, introduciendo, por ejemplo, técnicas de planificación y programación conjunta en todos aquellos sectores en los que convergen las competencias del Estado y de las Comunidades Autónomas.

Posteriormente, la Ley 30/1992 de Régimen Jurídico de las Administraciones Públicas y del Procedimiento Administrativo Común reconoce a las Conferencias Sectoriales como órganos de cooperación entre Estado y Comunidades Autónomas (art. 5). No obstante, la Ley las distingue de aquellos otros órganos colegiados creados por la Administración General del Estado para el ejercicio de sus competencias y en los cuales pueden participar representantes de la Administración de las Comunidades Autónomas con la finalidad de consulta (art. 5.1). Esta diferenciación acentúa el significado de las Conferencias Sectoriales como órganos creados por acuerdo mutuo y resalta el carácter político de las mismas.

Esta norma recoge también los siguientes aspectos en relación con el funcionamiento de las Conferencias Sectoriales contemplados previamente en el Acuerdo de 1992:

- La convocatoria se realizará por la persona titular del Ministerio (Ministro o Ministra) que tenga competencias sobre la materia que vaya a ser objeto de la Conferencia Sectorial. La convocatoria se hará con antelación suficiente y se acompañará del orden del día y, en su caso, de la documentación precisa para la preparación previa de la Conferencia.

- Los acuerdos que se adopten en una Conferencia Sectorial se firmarán por el Ministro o Ministra competente y por los titulares de los órganos de gobierno correspondientes de las Comunidades Autónomas. En su caso, estos acuerdos podrán formalizarse bajo la denominación de Convenio de Conferencia Sectorial.

- Las Conferencias Sectoriales podrán acordar la creación de comisiones y grupos de trabajo para la preparación, estudio y desarrollo de cuestiones concretas propias del ámbito material de cada una de ellas.

A partir de entonces, las Conferencias Sectoriales son reconocidas como mecanismos formalizados de cooperación vertical, multilaterales, de carácter sectorial y de naturaleza política (Ruiz González, 2012: 293).

\subsection{Trayectoria de las Conferencias Sectoriales}

Encontramos un universo con una trayectoria y ritmos distintos entre las 44 Conferencias Sectoriales y otros órganos asimilados según datos de MINHAP (2014): 28 Conferencias Sectoriales, 3 Consejos Consultivos para Asuntos Comunitarios, el Consejo Interterritorial del Sistema Nacional de Salud, la Conferencia para Asuntos relacionados con la Unión Europea (CARUE), la Comisión Nacional de Salvamento Marítimo, la Comisión de Recursos Humanos del Sistema Nacional de Salud, el Consejo de Política Científica, Tecnológica y de Innovación, el Consejo de Política de Seguridad, el Consejo Interterritorial de Internacionalización, la Conferencia General de Política Universitaria, el Consejo de Políticas del Juego, el Consejo Territorial de Servicios Sociales y del Sistema para la Autonomía y Atención a la Dependencia y el Consejo para la Unidad de Mercado.

Veamos una serie de aspectos que pueden resultarnos útiles para explicar tal diversidad:

1. Temática: han transcurrido 33 años de funcionamiento de estos órganos de coordinación sectorial desde que en 1981 se crea la primera Conferencia Sectorial hasta la actualidad. Dado que han sido creadas por un criterio sectorial, la mayoría de las Conferencias han mantenido sus cometidos, salvo el caso de cinco de ellas que o bien han sido suprimidas, o refundidas o sustituidas por otras.

2. Origen, forma y número de reuniones celebradas a lo largo de estos años: desde los años 80 hasta la actualidad no han dejado de crearse Conferencias Sectoriales. ${ }^{3}$ Aun así, existen Conferencias que, aun habiendo sido creadas, todavía no han tenido una sola reunión y por lo tanto no figuran como constituidas formalmente. ${ }^{4}$ Algunas Conferencias han sido creadas por imposición legal y otras por acuerdo entre las partes. ${ }^{5}$ Lo cierto es que, como señalan Duque (2007:124) y Arbós et al (2009:144) "La forma de creación de las Conferencias Sectoriales por ley estatal o por acuerdo de institucionalización del Estado y de las

3 El Consejo de Política Fiscal y Financiera fue creado en 1981 y la primera Conferencia Sectorial propiamente dicha, la Conferencia Sectorial de Agricultura, se creó el 1983. Las últimas en crearse han sido el Consejo para la Unidad de Mercado y la Conferencia Sectorial de Trafico, Seguridad Vial y Movilidad Sostenible, que datan de 2013 y 2014 respectivamente.

4 Este es el caso de la Conferencia Sectorial de Política Patrimonial y la Conferencia Sectorial del Agua.

5 Las Conferencias de Política Patrimonial, Salvamento Marítimo y Seguridad, creadas por imperativo legal, apenas han celebrado reuniones desde su creación, sin embargo, otras Conferencias creadas por acuerdo mutuo, como es el caso de las Conferencias de Agricultura; Pesca o Medio Ambiente, figuran entre las Comisiones con mayor número de reuniones entre la fecha de su creación y la actualidad. 
Comunidades Autónomas, no permite entender o explicar su mayor o menor funcionalidad y operatividad, o dicho de otro modo su grado de institucionalización y legitimidad".

El número de reuniones varía de forma importante entre unas y otras. Si nos atenemos al número de reuniones por año del total de Conferencias Sectoriales, se observan, según datos del MINHAP (2014), dos periodos con un porcentaje de reuniones por año muy diferente como podemos ver en el siguiente gráfico.

GRÁFICO 1. NUMERO DE REUNIONES DE LAS CONFERENCIAS SECTORIALES POR AÑo (1981-2014)

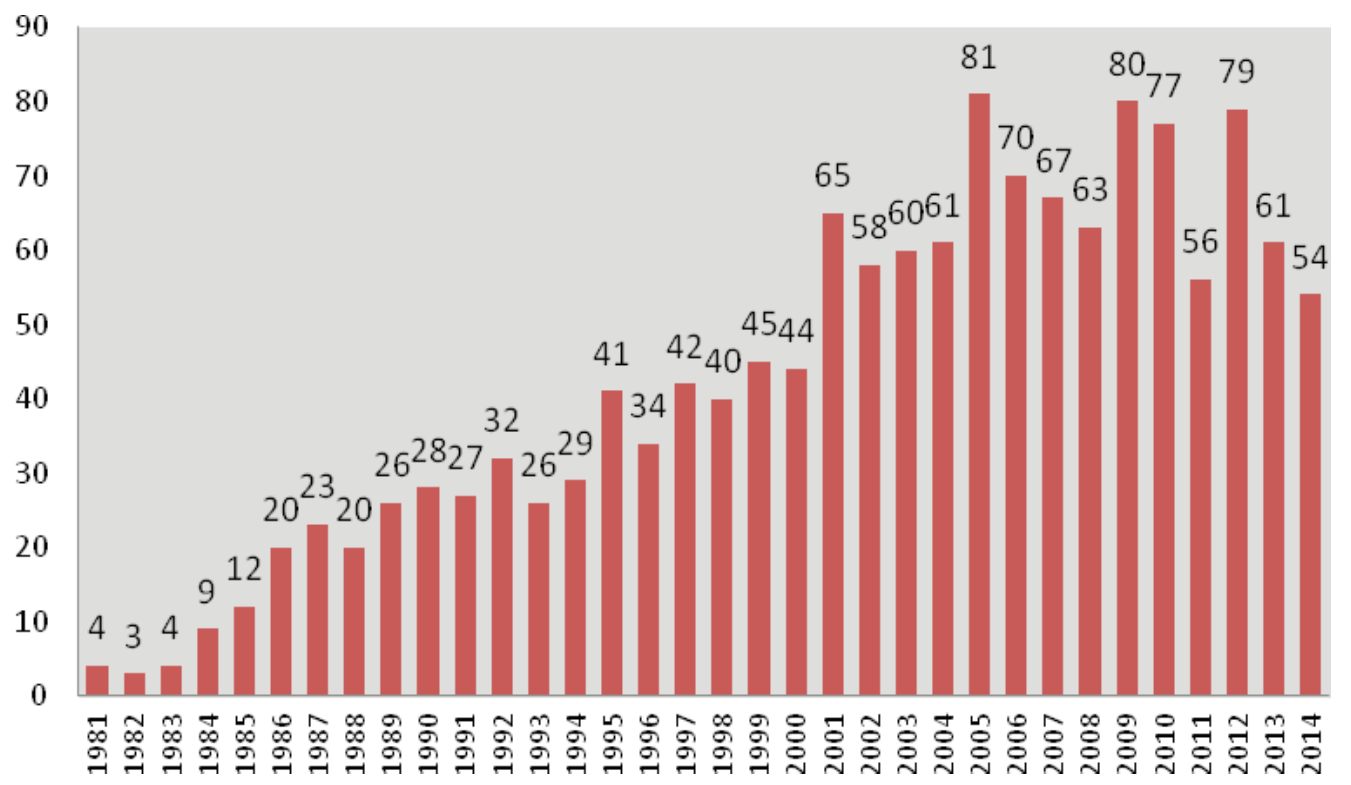

Fuente: Elaboración propia a partir de los datos ofrecidos por el MINHAP (2014).

El primer periodo comprende desde el año 1981 hasta el año 2000. En esta etapa el promedio de reuniones por año fue de 25 reuniones, una media baja aunque con un ritmo creciente de año en año. Tal inactividad motivó una serie de iniciativas parlamentarias solicitando información sobre el grado de cumplimiento de lo previsto en el art. 4 de la Ley 12/83, sobre la reunión periódica, al menos dos veces al año, de las Conferencias Sectoriales. La segunda etapa se inicia a partir del año 2001 y dura hasta la actualidad, 2014, con una media de reuniones muy superior a la etapa anterior: 66 reuniones por año. Con estas cifras, podemos concluir que las Conferencias Sectoriales comienzan a funcionar regularmente a partir del año 2001. ${ }^{6}$

3. Órganos preparatorios y de apoyo: el artículo 5.6 de la Ley de Régimen Jurídico de las Administraciones Públicas y del Procedimiento Administrativo Común se refiere a los órganos creados por las Conferencias Sectoriales como órganos de apoyo encargados del debate técnico de los diferentes temas que posteriormente van a ser tratados por el nivel político de las propias Conferencias. La denominación más usual para este tipo de órganos es la de Comisiones Sectoriales y están habitualmente constituidas por Directores Generales. La cooperación orgánica se completa con otro nivel, constituido por los Grupos de Trabajo y Ponencias Técnicas, dependientes también de las Conferencias Sectoriales, formados por niveles administrativos o técnicos especializados. En todo caso, interesa resaltar que todos estos órganos de nivel inferior forman parte del entramado de las propias Conferencias Sectoriales y su función es la de preparar y facilitar el trabajo de los Plenos de las Conferencias.

4. Existencia y contenido de sus Reglamentos: en primer lugar, no todas las Conferencias cuentan con un Reglamento de funcionamiento o al menos no se tienen datos sobre la existencia de estos, tal y como se recoge en la información facilitada por el MINHAP (2014). Los Reglamentos de las Conferencias Sectoriales tienen una estructura bastante similar. Todos ellos recogen la naturaleza de las Conferencias y sus fines, composición y funciones, órganos en los que se estructura; convocatoria y orden del día y régimen de adopción de acuerdos. No existen grandes diferencias en cuanto a cómo tratan estos puntos salvo, por ejemplo, en los tipos de órganos de segundo nivel que crean o el rango político de sus participantes. 
5. Asistencia y ausencia en las reuniones: los datos relativos a asistencia y ausencia de las Comunidades Autónomas en las Conferencias Sectoriales son escasos ${ }^{7}$ y difícilmente extrapolables para explicar dinámicas de funcionamiento distintas entre Conferencias. Este hecho ha motivado un análisis pormenorizado de la asistencia a las reuniones de las tres conferencias analizadas.

6. Acuerdos y toma de decisiones: como destacan Colino y Parrado, existen diferencias en cuanto a los procedimientos regulados en los Reglamentos para la toma de decisiones según a qué Conferencia nos estemos refiriendo aunque la práctica común en principio sea el consenso entre los participantes (Colino y Parrado, 2009: 181). Aun prevaleciendo esta opción se encuentran diferencias, puesto que algunas Conferencias contemplan que si este consenso no se alcanzara y hubiera que optar por las votaciones, unas optan por las mayorías simples, otras por mayorías absolutas de los miembros presentes y en otras se establecen minorías de bloqueo o votos de calidad.

7. Representación de las CCAA en la UE: la Conferencia Sectorial para asuntos relacionados con la Unión Europea se define, en virtud de la Ley 2/1997, como un órgano de cooperación de composición horizontal, y que tiene como finalidad esencial garantizar la participación de las Comunidades Autónomas en la formación de la voluntad estatal ante las instituciones comunitarias y en la ejecución del derecho comunitario, así como ofrecer a las Comunidades Autónomas un foro en el que el Estado pueda informar y oír las opiniones autonómicas sobre los grandes temas del proceso de construcción europea que por su naturaleza institucional no pueden ser abordados en las Conferencias Sectoriales específicas.

Esta Conferencia ha adoptado dos acuerdos (1994 y 2004) sobre la participación de las Comunidades Autónomas en el proceso decisional comunitario, en relación a los cuales cada conferencia sectorial ha decidido sobre la forma de aplicación en su funcionamiento interno.

Podemos concluir diciendo que todos estos aspectos destacados evidencian que la trayectoria de las Conferencias Sectoriales obedece a ritmos y características diversas.

\section{DINÁMICA DE FUNCIONAMIENTO DE LAS CONFERENCIAS SECTORIALES}

Las Conferencias Sectoriales presentan grandes diferencias en cuanto a su actuación puesto que el sector y, fundamentalmente el régimen competencial que lo regula, resultan claves para analizar la actividad que llevan a cabo. No obstante, todas ellas en general presentan una serie de características comunes en lo que se refiere a su funcionamiento. En este apartado se ofrece la descripción del funcionamiento de las tres Conferencias analizadas en el trabajo de campo de este estudio, es decir, la Conferencia Sectorial de Educación, la Conferencia Sectorial de Medio Ambiente y el Consejo Interterritorial del Sistema Nacional de Salud, teniendo en cuenta los aspectos formales recogidos en la normativa correspondiente, fundamentalmente las leyes y los Reglamentos de las mismas, el análisis de los órdenes del día y la valoración sobre su funcionamiento real y práctico que se recoge en las entrevistas.

El Ministerio de Administraciones Públicas elaboró en 2006 un documento en el que se comparaban los contenidos de los textos siguiendo la clasificación de seis elementos: naturaleza jurídica, las funciones de las Conferencias Sectoriales, su composición, las reglas de funcionamiento, los órganos de apoyo y la toma de decisiones. ${ }^{8}$ Seguiremos esta clasificación en el análisis de las características de las tres conferencias aquí consideradas.

\subsection{Naturaleza jurídica}

Teniendo en cuenta la base legal de la que se originan, dos de las tres Conferencias Sectoriales analizadas fueron creadas por ley sectorial derivada de las competencias estatales en la materia correspondiente: Consejo Interterritorial del Sistema Nacional de Salud y Conferencia Sectorial de Educación (Arbós et al. 2009: 143). En todo caso, como se ha dicho anteriormente, la forma de creación no tiene una incidencia determinante en el funcionamiento, operatividad y grado de institucionalización de este tipo de órganos (Duque, 2007: 124). De acuerdo con lo que ya se ha expuesto antes, en los tres casos existe un reglamento interno de funcionamiento aprobado por cada Conferencia.

\subsection{Funciones}

De acuerdo con el análisis de los objetivos y funciones de las Conferencias Sectoriales determinadas en sus reglamentos y observados los órdenes del día puede señalarse que existen los siguientes:

7 Los que han sido hechos públicos, mediante informe de seguimiento de la actividad de estas Conferencias, únicamente recogen lo relativo al año 2002. A este respecto, únicamente los datos sobre asistencia extraídos de cada una de las actas de las reuniones podrían posibilitar una comparación entre Conferencias y entre Comunidades Autónomas que permitieran sacar conclusiones con cierto rigor científico.

8 Ministerio de Administraciones Públicas. 2006. Reglamentos de las Conferencias Sectoriales: Textos comparados, pág. de 1 a 3. 
1. En el marco de la función de intercambio de información se ubica la actividad de informar y/o lograr consenso en torno a normas, ya sean Leyes o Reales Decretos; esta es una labor a la que las Conferencias dedican mucho tiempo cuando el Ministerio afronta la aprobación de una propuesta de una reforma legal.

2. En cuanto a la función de participación de las Comunidades Autónomas en las decisiones del Estado, podemos considerar que se refleja en el apartado de ruegos y preguntas, categoría que a su vez engloba el propio funcionamiento de la Comisión.

3. Los asuntos internacionales en la mayoría de las ocasiones guardan relación con la participación en asuntos comunitarios; de esta forma, las Conferencias Sectoriales podrían interpretarse como uno de los elementos para frenar la posible recentralización que supone la asunción por parte de las Instituciones Europeas de competencias autonómicas. Así, una de las funciones es preparar las reuniones del Consejo Europeo en el que el Ministerio estará acompañado por una Comunidad Autónoma sobre la que recaerá la representación.

4. La aprobación o la información de planes de actuación es otra función asignada a las Conferencias Sectoriales y que adquiere considerable relevancia según etapas y áreas de intervención. Esta actividad refleja las funciones de intercambio de información y de establecimiento de criterios comunes de actuación.

5. La gestión y distribución de fondos es otra de las funciones asignadas a las Conferencias Sectoriales. Aunque los fondos europeos tienen gran peso, también puede tratarse de inversiones de ámbito estatal, como la financiación de algún programa, por ejemplo, sanitario.

6. La gestión de catástrofes, accidentes o alarmas, situaciones que requieren la coordinación urgente de las Comunidades Autónomas y el Estado es una responsabilidad que se encamina a través de las propias Conferencias Sectoriales. Esta actividad también puede enmarcarse en la función de establecimiento de criterios comunes de actuación así como en la de intercambio de información.

Una de las funciones que en mayor medida se presenta en los órdenes del día de las convocatorias de las Conferencias Sectoriales es la de informar leyes y decretos estatales. Las Conferencias Sectoriales informan las propuestas de ley del gobierno, y también los decretos que desarrollan estas leyes. Tal como señala una de las personas entrevistadas:

"Sí, el propio reglamento de la Conferencia Sectorial lo prevé. Cuando los Consejeros y el Ministro que elaboraron el reglamento se pusieron de acuerdo, consideraron que por lo menos las leyes que elaborara el Ministerio debían ser informadas por la Conferencia Sectorial” (Entrevista n. ${ }^{\circ} 08^{9}$ ).

Sin embargo, cuando se trata de materias compartidas o de las Comunidades Autónomas la actitud sobre la permeabilización de las propuestas así como la actitud negociadora y de consenso varía.
"Había algunos aspectos en los que las Comunidades Autónomas, me estoy refiriendo a la trasposi- ción de las directivas comunitarias, habían hecho una estrategia previa a la del Estado. Por ejemplo, por hablar solamente de la Comunidad de Madrid en materia de ruidos, ya tenía una normativa, pre- via a la del Estado y, en algunos aspectos, más exigente. Desde ese punto de vista, no es que hubiese una capacidad de iniciativa por parte de las Comunidades Autónomas, pero sí había una capacidad de contraposición entre la normativa estatal y la normativa autonómica a efectos de llegar a una especie de acuerdo" (E11).

Respecto al posicionamiento de las Comunidades Autónomas a la hora de informar una ley estatal, según qué materia se trate se encontrará mayor o menor alineamiento en torno al partido político. Las personas entrevistadas hacen referencia al grado de politización, así en aquellas cuestiones que consideran están muy politizadas el peso de la disciplina de partido será mayor. La alineación partidista a la hora de informar leyes tiene un importante riesgo en la medida en que vacía de contenido a la Conferencia Sectorial, ya que reproduce el debate que se desarrolla en otros ámbitos como es el Congreso de Diputados o incluso en el propio Senado.

"Es que no tiene sentido, cuando después todos esos grupos tienen sus grupos parlamentarios en el Congreso y en el Senado (...) Qué más da, si al final es la posición que van a llevar los partidos políticos." (E10).

9 A partir de este momento, las citas entresacadas de las entrevistas en profundidad incluidas en el texto estarán identificadas con una $\mathrm{E}$ que significa entrevista y con el número de entrevista. 
Atender la esfera internacional es otro de los ámbitos de actuación de las Conferencias Sectoriales. De acuerdo con la información obtenida de los órdenes del día de las reuniones de las Conferencias Sectoriales y a la luz de la opinión de las personas entrevistadas los Asuntos de la Unión Europea tiene un papel relevante en el quehacer de estos organismos. En este ámbito, el análisis de las diferentes conferencias adquiere relevancia; de este modo, mientras en Educación y en Sanidad la incidencia de las decisiones europeas son más limitadas su presencia en Medio Ambiente es crucial.

"Por tanto, no había efectos de importantes directivas europeas sobre educación. Los indicadores que ofrecía la Comisión como objetivos a perseguir eran tratados también. Pero directivas, muy pocas" (E11).

Los planes de actuación son otro importante parte del orden del día. El concepto de aprobación o información sobre planes ha sido amplio a la hora de analizar los órdenes del día. De tal forma que a los planes de actuación interinstitucional se les ha sumado los programas de actuación en proyectos concretos como puede ser la vacunación o protocolos comunes de actuación.

"Sí, bueno y algunos elementos (positivos) hicimos, planes directores estratégicos, ya sabes, de grandes grupos de enfermedades, que allí teníamos que compartir, la estrategia nacional de cáncer, de cuidados paliativos." (E14).

Otra de las funciones fundamentales de las Conferencias Sectoriales es la distribución de fondos, bien en relación a los fondos del Estado (fuente importante para algunas Comunidades Autónomas) bien en relación al reparto de fondos cuyo origen es la Unión Europea. Esto sitúa a las Comunidades Autónomas en diferente situación: aquellas que pertenecen al régimen común y aquellas que pertenecen al régimen foral y funcionan mediante el Concierto Económico, a quienes no incide. La relevancia de los fondos que provienen desde el Estado para las Comunidades Autónomas de régimen común dentro de las Conferencias Sectoriales se ha ido aminorando una vez se ha materializado el traspaso total de la competencia.

“Es que aquí hay un juego muy especial. Porque el Ministerio tiene ciertos fondos, ciertos recursos, apetitosos para cada Comunidad que teóricamente deberían ir por criterios LOFCA distribuidos de la forma ordinaria, pero que no se colocan en el apartado de Comunidades Autónomas, sino que se coloca en el apartado 'Ministerio de Educación', con estos dineros puede jugar a hacer sus programas" (E12).

La temática también es relevante a la hora de hablar de reparto de fondos. De esta forma, mientras esta función ha sido relevante en Educación y en Sanidad, en Medio Ambiente no se ha tenido tanta relevancia, por lo menos, en lo que se refiere a debatir el reparto de fondos del Estado.

"Yo, en materia de Medio Ambiente, el reparto de fondos... no recuerdo... En materia de prevención de incendios, lo que hubo fue la creación de la Unidad Militar de Emergencia. No recuerdo que hubiese reparto de fondos (... ) La protección medioambiental es muy cara y entonces, llega un momento en que muchas veces se dice: 'No podemos' (...) Pero yo no recuerdo, en mi participación en las Conferencias Sectoriales que haya habido ese reparto de fondos" (E11).

Finalmente, entre las funciones asignadas a las Conferencias Sectoriales y analizadas a través de los órdenes del día se sitúan lo que se ha denominado accidentes o crisis que exigen una respuesta rápida y coordinada. En el periodo estudiado la gripe A, por ejemplo, ha sido uno de los elementos que han copado las reuniones monotemáticas en ocasiones tanto de la Conferencia Interterritorial del Sistema Nacional de Salud como de la Conferencia de Educación, sin embargo, no parece ser un elemento al que las personas entrevistadas hayan prestado atención.

\subsection{Composición y asistencia}

Los reglamentos de las Conferencias Sectoriales analizadas establecen que los plenos de las Conferencias están constituidos por la persona titular del ministerio correspondiente, en calidad de presidente de la misma, y los consejeros competentes en representación de las Comunidades Autónomas. La posibilidad de la delegación de la participación de los consejeros autonómicos en algún miembro de rango inferior de su consejería, además de en otro miembro del consejo de gobierno de su comunidad autónoma estaba recogida únicamente en el reglamento de la Conferencia de Educación, pero a tenor de los datos disponibles era una 
práctica que en mayor o menor medida se extendía al resto de las Conferencias. La reforma de los reglamentos del Consejo Interterritorial de Salud y de la Conferencia de Medio Ambiente, en palabras de uno de nuestros entrevistados, tenía como objeto “dotarles de un carácter más político” y promover una mayor presencia de los titulares de las consejerías en los plenos. De esta manera el reglamento vigente del Consejo de Salud no recoge la posibilidad de la delegación y el de la Conferencia de Medio Ambiente permite delegar en personas con rango de consejero, pertenecientes bien al consejo de gobierno de su comunidad bien a la Conferencia Sectorial.

La tabla 1 recoge los datos de asistencia a las tres conferencias analizadas según el rango de sus participantes. En los casos de las conferencias de Salud y Medio Ambiente se han diferenciado los periodos en los que han estado vigentes reglamentos distintos.

TABLA 1. CONFERENCIA SECTORIAL DE EDUCACIÓN, CONFERENCIA SECTORIAL DE MEDIO AMBIENTE Y CONSEJO INTERTERRITORIAL DE SALUD (2001-2012). ASISTENCIA POR RANGO.

\begin{tabular}{|c|c|c|c|c|c|c|c|c|}
\hline & \multicolumn{4}{|c|}{ Asistencia } & \multirow{2}{*}{\multicolumn{2}{|c|}{ No asiste }} & \multirow{2}{*}{\multicolumn{2}{|c|}{ Total }} \\
\hline & \multicolumn{2}{|c|}{ Consejero/a } & \multicolumn{2}{|c|}{ Otros/as. } & & & & \\
\hline & $\mathrm{N}$ & $\%$ & $\mathrm{~N}$ & $\%$ & $\mathrm{~N}$ & $\%$ & $\mathrm{~N}$ & $\%$ \\
\hline Educación (32) & 443 & 81,4 & 93 & 17,1 & 8 & 1,5 & 544 & 100,0 \\
\hline Salud (a) (7) & 104 & 82,5 & 18 & 14,3 & 4 & 3,2 & 126 & 100,0 \\
\hline Salud (b) (40) & 668 & 87,9 & & & 92 & 12,1 & 760 & 100,0 \\
\hline Medio Ambiente (a) (21) & 301 & 75,6 & 61 & 15,4 & 36 & 9,0 & 398 & 100,0 \\
\hline Medio Ambiente (b) (6) & 58 & 50,9 & 18 & 15,8 & 38 & 33,3 & 114 & 100,0 \\
\hline
\end{tabular}

Fuente: elaboración propia.

Salud (a): Periodo anterior al cambio de reglamento. (15/04/2002-23/07/2003). Salud (b): Periodo posterior al cambio de reglamento. (3/12/2003-20/12/2012). Medio Ambiente (a): Periodo anterior al cambio de reglamento. (01/02/2001-06/09/2007). Medio Ambiente (b): Periodo posterior al cambio de reglamento. (07/06/2010-15/10/2012). Los números entre paréntesis indican el número de plenos realizados bajo cada reglamento.

A la vista de los datos globales comparados de las conferencias se observa que los mayores porcentajes de asistencia se producen en los momentos en los que las prácticas de delegación son más permisivas. En efecto, la no asistencia (comparamos los datos que ofrecen el Consejo de Salud antes y después del cambio reglamentario así como los que presenta la Conferencia de Medio Ambiente) alcanza los mayores porcentajes tras la aprobación de las modificaciones reglamentarias, destacando el último periodo analizado de la Conferencia de Medio Ambiente con un $33,3 \%$ de inasistencias.

A su vez, el objetivo que justificaba los cambios de reglamento no parece reflejarse plenamente en los resultados obtenidos. El impacto de dichas medidas tiene efectos contrapuestos, así mientras el porcentaje de asistencia de los consejeros aumenta en los plenos del Consejo de Salud (de un 82,5\% a un 87,9\%) disminuye notablemente en los de la Conferencia de Medio Ambiente (del 75,6\% al 50,9\%). Si bien no disponemos de datos concretos que puedan explicar este comportamiento dispar, alguno de nuestros informantes plantea una posible explicación: mientras que, debido a su naturaleza, la mayoría de los temas tratados en el Consejo de Salud atañen en igual medida a todas las Comunidades Autónomas, los tratados en la Conferencia de Medio Ambiente pueden no atraer el interés de todas ellas por lo que el orden del día podría incentivar o no la participación.

Por otra parte, podemos descubrir comportamientos diferenciados entre las Comunidades Autónomas en cada una de las Conferencias analizadas. En la valoración que nuestros entrevistados y entrevistadas hacen sobre la asistencia a las Conferencias Sectoriales, se observa que la inasistencia o la delegación en cargos de rango inferior a la consejería es presentada como una forma de mostrar el desacuerdo con el modelo homogeneizador que supone a su entender la propia Conferencia. Es una práctica que representantes de Cataluña y de la Comunidad Autónoma de País Vasco han Ilevado a cabo en la Conferencia de Educación y que estos últimos trasladaron también a la de Medio Ambiente.

“...mi posición al respecto era no ir a la Conferencia de Educación, salvo que fuera algo de mucho peso, de mucho peso político. (...) Entonces, queríamos mantener si podíamos más la relación bilateral con el ministro o la ministra de turno, que ir a una conferencia donde quedábamos difuminados entre 17 Autonomías" (E01). 
"Es que yo cuando fui consejera creo que solo fui a una. O a ninguna. Pero eso ya era también posición política”. (E10)

"De hecho, en algunos momentos me consta que el País Vasco hizo este papel, de decir: "Ahí está el Ministerio, ahí está la Conferencia, ahí se las compongan. Yo no... a mí no me interesa participar, yo tengo mi sistema montado y participar allí es legitimar una situación de la que discrepo porque, a fin de cuentas, es cierto, un consenso lamina las competencias que ya tengo". (E12)

No obstante, la inasistencia es también utilizada como instrumento para expresar el desacuerdo con el Ministerio, la discrepancia entre el gobierno y la oposición, para escenificar la lucha partidaria. Por ejemplo, a las convocatorias del Consejo de Salud del 22 de setiembre de 2004 y del 2 de junio de 2011, Madrid, La Rioja, Murcia, Valencia, Castilla-León, Ceuta y Melilla en los dos casos y Galicia y Baleares en uno de ellos, las comunidades gobernadas por el Partido Popular no envían ningún representante (Mondragón, Elizondo, De la Peña, Juaristi, Mokoroa, 2015: 147).

“Llegamos a hacer un Consejo Interterritorial en Barcelona donde no asistió el PP.” (E05).

De la misma manera de las 7 comunidades (exceptuando el caso de la Comunidad Autónoma del País Vasco arriba comentado, Galicia, Murcia, Navarra, Valencia, Ceuta y Melilla) que presentan un porcentaje de presencia de consejeros inferior a la media 6 corresponden al Partido Popular y UPN acentuándose la representación de un rango de nivel inferior durante el periodo correspondiente a la ministra Cristina Narbona.

\subsection{Convocatoria y orden del día}

Los Reglamentos analizados señalan que la convocatoria de las reuniones de las Conferencias corresponde a la Presidencia que es responsable a su vez del establecimiento del orden del día. Las reuniones de las Conferencias de Educación y Medio Ambiente habrán de ser como mínimo dos al año, periodicidad que aumenta a 4 en el Consejo Interterritorial del Sistema Nacional de Salud. Las convocatorias han de realizarse con una antelación mínima diferente en cada caso: 3 días en Salud, 7 días en Medio Ambiente y 10 días en Educación.

Tanto el Reglamento de la Conferencia de Educación como el de la Conferencia de Medio Ambiente recogen la posibilidad de que los miembros de las Conferencias puedan proponer la inclusión de temas en el orden del día mientras que el de Salud no hace mención al respecto.

Todas las personas entrevistadas señalan que, de acuerdo con las regulaciones en las que se basan las distintas Conferencias Sectoriales, es el Ministerio el que hace la convocatoria y determina el orden del día de las reuniones. Concretamente, es el Secretario de Estado de cada Ministerio el que, en nombre del Ministro o de la Ministra de turno, convoca a las Comunidades Autónomas a la reunión. La labor de las secretarías de las Conferencias consiste en enviar a las Comunidades Autónomas las convocatorias y la documentación sobre los temas a tratar, asistir a las reuniones, escribir las actas y, con posterioridad, archivar y custodiar toda la documentación generada.

Un aspecto que los Consejeros y Consejeras creen que se podría mejorar se refiere al plazo de la convocatoria. Son conscientes de que las regulaciones señalan que la convocatoria se debe hacer con suficiente antelación para que los representantes de las Comunidades Autónomas tengan tiempo suficiente para estudiar la documentación y los temas que se van a abordar en la reunión. Sin embargo, tal y como señala la entrevistada n. ${ }^{\circ}$ :

"El Reglamento de la Conferencia dice: 'que los asuntos se llevarán bien preparados, tras haber sido debatidos en la Comisión General'. Bueno, todo eso, en la última etapa que yo he vivido de Wert se ha visto vulnerado. Ni los asuntos habían sido debatidos convenientemente, ni siquiera en la Comisión General, ni había documentación disponible, ni cita diez días antes (...). Íbamos a la Conferencia Sectorial sin haber sido informados. Casi, casi, ni teníamos documentación... el orden del día se había pasado con 48 o 72 horas" (E02).

Sobre los temas a tratar en la reunión, la mayoría de las personas entrevistadas señala que el orden del día de las reuniones viene determinado, fundamentalmente, por los asuntos tratados previamente en la comisión, aunque la última palabra la tiene el ministerio, que es el que fija y altera, en función de sus intereses y necesidades, el orden del día, incluyendo temas que puede que no se hayan tratado en la comisión. Las decisiones tomadas en las instituciones europeas también influyen en la agenda de las conferencias. Tal y como señala una de las personas que trabajan a nivel técnico en la organización de las Conferencias Sectoriales: 
" (... ) sí existe la posibilidad de incluir puntos que no se hayan tratado en la Comisión preparatoria. Se hace con un carácter excepcional, para que la función de la Comisión se respete, y porque ese valor técnico que tiene la Comisión es muy importante. (...).Y también, lógicamente, si hay algún punto que el Ministro quiere incluir y considera que no se debe debatir en absoluto a nivel técnico, porque es un tema de un carácter político evidente, se incluye directamente en el orden del día de la Conferencia Sectorial, y ya está. Lo prevé el Reglamento y es posible. El orden de día, de todas maneras, finalmente siempre lo fija el Ministro; o sea que el Ministro supervisa todos los temas, y decide las cuestiones que quiere incluir..." (E07).

Las Comunidades Autónomas también pueden incorporar temas en el orden del día, y de hecho así está previsto en los Reglamentos, pero no es habitual que ocurra. Tal y como señala el entrevistado $n .^{\circ} 7$ :

“La posibilidad existe, y las Comunidades Autónomas pueden incluir temas en el orden del día, una vez que reciben el orden del día. Está previsto en el Reglamento, tienen un plazo para proponer asuntos, pero no es habitual que ocurra. Lo normal es que la iniciativa la lleve el Ministerio" (E07).

Sobre todo los Consejeros y Consejeras nacionalistas se quejan de que tienen poca capacidad de incidir en la agenda de las conferencias. De todas formas, parece ser que lo más habitual es que los temas que interesan a las Comunidades Autónomas o los temas de más actualidad que no han podido ser incluidos en el orden del día se traten en el apartado de ruegos y preguntas.

"Siempre se termina con un apartado de ruegos y preguntas. Que ese suele ser el apartado más abierto porque ahí es donde se tratan los temas de actualidad que a lo mejor no ha dado tiempo a meter en el orden del día" (E15).

\section{5. Órganos de preparación y apoyo}

Una cuestión importante en el funcionamiento de las Conferencias Sectoriales es la organización de las mismas, las estructuras de apoyo que se crean para desarrollar su trabajo. Estos órganos de apoyo llevan a cabo una importante labor de carácter preparatorio, fundamentalmente técnico y sus aportaciones resultan imprescindibles en el proceso de toma de decisiones. Hay Conferencias Sectoriales que cuentan con una decena de estos órganos, caso de la Conferencia de Educación, frente a otras que no tienen ninguno como la Conferencia de Política de Seguridad. ${ }^{10}$

En el caso de las tres Conferencias Sectoriales que nos ocupan, todas ellas cuentan con una Comisión Sectorial de carácter general así como diferentes órganos de contenido especial. Los que forman parte de estas Comisiones o grupos técnicos pueden formar parte o no de la Comisión Sectorial General o de la Conferencia Sectorial, pero en los grupos se da también una representación territorial. Aunque la discusión de los temas revista un carácter técnico, en algunos casos algunas Comunidades Autónomas se desmarcan por razones de oposición al tema.

Volviendo a las primeras, las Comisiones Sectoriales de carácter general, la preparación del orden del día de esta se elabora en contacto con la Secretaria de la Conferencia Sectorial. Su papel es trabajar desde un punto de vista técnico y elevar los asuntos para su discusión política a la Conferencia Sectorial.

Si algún asunto es más importante requiere que se eleve a Comisión Sectorial. El Reglamento ordena elevar los temas a la Conferencia, bien como informados, aprobados o rechazados.

\subsection{Toma de decisiones}

De conformidad con lo establecido en el artículo 5 de la Ley 30/1992, los acuerdos de las Conferencias Sectoriales se adoptan por asentimiento de los miembros de la Conferencia y, en su defecto, por el voto favorable de la Administración del Estado y de la mayoría de las Comunidades Autónomas. Estas decisiones pueden adquirir la forma de recomendaciones o si son acuerdos de cooperación para llevar a cabo acciones conjuntas tienen la denominación de convenios de Conferencia.

Los acuerdos surten efecto sólo para los miembros que hayan expresado su voto favorable. Aquellas Comunidades Autónomas que no hubieran expresado su voto favorable podrán adherirse con posterioridad al acuerdo.

10 Según datos recogidos en el Informe sobre la Actividad de las Conferencias Sectoriales durante el año 2012. http://www.seap.minhap.gob.es/dms/es/areas/politica autonomica/coop autonomica/Conf Sectoriales/Documentacion/Conf Sect anuales/parrafo/o/text es files/INFORME-CONFERENCIAS-SECTORIALES-2012/INFORME\%20CONFERENCIAS\%20SECTORIALES\%202012.pdf. 
Si bien el Reglamento permite que los temas pasen como informados, aprobados o rechazados, la mayoría de las veces las actas de las Conferencias Sectoriales muestran que los temas han pasado como informados o aprobados. Si son aprobados, lo son por mayoría. Tal y como señala la entrevistada n. ${ }^{\circ}$ :

"Normalmente se expone el punto, y lo que habla el Reglamento es de elevar los temas a la Conferencia, y pasan como informados o aprobados o rechazados... Informados no requiere votación, simplemente es exponerlo. No obstante, en el acta se recoge la intervención de cada comunidad que quiera intervenir. Y si es aprobado, de alguna manera, lo es por mayoría normalmente" (E06).

Los temas son presentados por el Ministro o Ministra, se debaten y, si no hay grandes discrepancias, el acta señala que han sido aprobados. De hecho, la mayoría de los Consejeros y Consejeras entrevistados no recuerdan que hayan votado en las Conferencias Sectoriales. En la mayoría de los casos el Ministerio presenta sus propuestas y los representantes de las Comunidades Autónomas dan su opinión pero no hay votación. Tal y como señala el entrevistado . $^{\circ} 3$ :

"Yo creo que no había votación. Es decir, las distintas comunidades opinaban, si querían, lógicamente, de la ley. Interveníamos prácticamente todos. Y yo no recuerdo que se votase...” (E03).

La mayoría de las veces, las personas que participan en las conferencias asienten a lo que ha informado el Ministro. Las conferencias buscan en todo momento el consenso y cuando hay temas conflictivos se intentan resolver las discrepancias en la comisión, es decir, en la reunión preparatoria de la Conferencia Sectorial; cuando esto no es posible se llega a un consenso dentro de la propia Conferencia. Es decir, incluso cuando se tratan temas conflictivos lo normal es que se apruebe de manera consensuada, por mayoría de todos los representantes de las conferencias. Tal y como señala la entrevistada n. ${ }^{\circ}$ :

"Un tema de reparto de fondos, por ejemplo, en el capítulo 7, una transferencia de capital entre comunidades: en alguna ocasión se ha dado el caso de que ha habido diferencia de criterios entre Andalucía y Castilla-La Mancha en la Comisión, y llegada la Conferencia se liman posturas" (E06).

El hecho de que se tomen las decisiones por asentimiento de los participantes y de que la última palabra la tenga el Ministerio genera distintos tipos de críticas entre los Consejeros y Consejeras. Por una parte, se critica el hecho de que no se vote en las reuniones de las conferencias.

“No se votaba nunca, yo nunca vi una votación, eran más bien posicionamientos de... si hubiera habido una votación, claro, la perdían los Consejeros, porque el gobierno central tenía 17. Y esto siempre se había criticado, y lo habíamos escrito, y lo habíamos dicho, que esto no acababa de funcionar" (E08).

En este sentido, algunos Consejeros y Consejeras señalan que esta búsqueda del consenso permite a los representantes de las Comunidades Autónomas introducir algunos cambios en las propuestas del ministerio, pero impide que se recojan las propuestas de forma correcta y satisfactoria para las comunidades discrepantes. Tal y como señala el entrevistado n. ${ }^{\circ} 14$ :

"Las decisiones se tomaban por consenso, y por tanto había un porcentaje de cuestiones en las que tú podías convencer al Ministerio o al resto de colegas que era interesante que se hicieran determinados cambios... que se introdujeran determinados elementos. Esto tenía pros y contras; es decir, (...) esto comportaba que el consenso fuera bueno, por una parte, porque conseguías introducir algunas cosas, y fuera malo, por otra, porque nunca conseguías introducirlas correctamente" (E14).

Otro aspecto criticado sobre la toma de decisiones es el hecho de que los Consejeros y Consejeras de las Comunidades Autónomas adoptan una posición sobre los temas que se debaten en función de las consignas del partido político al que pertenecen más que función de los intereses de su autonomía.

“(...) en aquel momento gobernaba el Partido Socialista, y además era prácticamente también casi mayoritario en el conjunto de las Comunidades Autónomas. Pero, en general, el Partido Popular iba en bloque, es decir, normalmente cuando había alguna cuestión que querían oponerse se oponían en bloque. No era un proceso operativo. Allí no se representaba a la Comunidad de Madrid o se representaba a la Comunidad Valenciana, allí se iba a poner una serie de objeciones de carácter polí- 
tico, no territorial. Por otro lado, pasaba lo mismo con el PSOE, las Comunidades del PSOE apoyaban en muchos casos indiscriminadamente los planteamientos ministeriales más allá de que favorecieran o no favorecieran en absoluto sus propios planteamientos o su comunidad" (Eog).

Una de las consecuencias de que las posiciones frente a los temas se determinen en función del color político limita el debate y desnaturaliza el funcionamiento de las conferencias. Tal y como señala la entrevistada $n .^{\circ} 2$ :

"Lo que más ha desnaturalizado la Conferencia en los últimos tiempos, es que las Comunidades del Partido Popular iban con consigna prefijada, con lo cual el debate se vio muy condicionado, muy limitado, por los prejuicios políticos que llevaba cada una de las personas. Y el pactar los temas previamente por objetivos partidarios o partidistas, lo que hace es desalojar a la educación del ámbito propio en el que tiene que desarrollarse" (E02).

Para mejorar la toma de decisiones en las conferencias, y evitar todos los problemas que surgen de la búsqueda de falsos consensos y de planteamientos partidistas algún Consejero propone dar mayor autonomía a las conferencias.

“(... ) yo propondría una independencia mayor de la Conferencia con respecto del Ministerio. (...). Naturalmente, la Conferencia dependerá mucho de las iniciativas del Ministerio, en el sentido de que la iniciativa legislativa, la iniciativa normativa, que necesariamente tiene que pasar por la Conferencia, es del Ministerio (... ). Pero si se quiere trabajar en serio hacia fórmulas verdaderas de cooperación, intentaría darle una posibilidad de trabajo autónomo, de trabajo propio, de iniciativa. (...). Es decir, que la Conferencia tuviera algún elemento propio, de personalidad propia que le diera sentido a esta cooperación; si no, en fin, se hace la escenificación y ya está" (E12).

\section{EL FACTOR HUMANO EN EL FUNCIONAMIENTO DE LAS CONFERENCIAS SECTORIALES}

Definimos el factor humano como un conjunto de características de las personas integrantes de las Conferencias Sectoriales que condicionan su interacción y, en consecuencia, el funcionamiento de la propia institución. Nos referimos de esta manera a los componentes ideológicos y de identidad partidista que forman la identidad política de las personas involucradas en estos procesos políticos, a las habilidades sociales que puedan desplegar tales como la capacidad de diálogo, de empatía o el carisma o también a los currículos formativos y profesionales.

\subsection{Rasgos ideológicos: concepciones sobre la organización territorial y el alineamiento partidista}

En los análisis que las personas entrevistadas realizan sobre el funcionamiento de las conferencias destacan dos factores de carácter ideológico: en primer lugar, las concepciones sobre la organización territorial, las formas que debieran tomar las relaciones entre las comunidades autónomas y el gobierno central; en segundo lugar, el alineamiento de los actores en torno a las identidades ideológico-partidistas.

Existen percepciones diferentes en relación a las Conferencias Sectoriales en función de la ideología política de los representantes que participan en las mismas. El funcionamiento y la configuración que han adoptado las Conferencias Sectoriales son el resultado de una manera de entender el Estado de las Autonomías. La discusión sobre la naturaleza y alcance del Estado de las Autonomías se plasma en el campo de juego delimitado por las Conferencias y expresa sus distintas y contrapuestas lógicas, los objetivos que persiguen y la evaluación que realizan sobre estos órganos.

La visión que predomina entre los representantes territoriales que hemos entrevistado refleja que la creación de las Conferencias Sectoriales responde a un impulso, reprobado o aplaudido, que bajo el concepto de armonización busca un mayor control por parte del gobierno y de la administración centrales sobre los procesos de transferencia y desarrollo de las competencias. El resultado es la percepción unánime de la configuración de una estructura territorial de relaciones entre la administración central y las autonómicas de tipo jerárquico y vertical.

"Vamos a ver, yo creo que las Conferencias Sectoriales son un instrumento que se ha creado a través, o para una coordinación de una situación provenida después de la LOAPA, por llamarlo de alguna forma. Ocurre que, en definitiva, son elementos de homogenización del sistema político." (E01).

Según los interlocutores críticos esta concepción del Estado de las Autonomías se abre paso apoyada en una práctica y en una cultura política hegemónicas que la conciben como una manera cuasi-natural de estructuración política. 
“Muchas veces lo que realmente es el Estado es mucho más la administración y los altos funcionarios permanentes que no los propios cargos políticos (...) Es decir, aquí el único gobierno es el central. El resto son administraciones delegadas que llevan las competencias tasadas, pero no por maldad ni por... Es por pura respiración incluso, con la mejor intención: "Vamos a hacer algo interesante. Vamos a compartir"'" (E04).

En palabras de estos interlocutores, palabras que exigen una modulación en función de casos y momentos distintos, la práctica y el discurso de los actores partidistas (Partido Popular y Partido Socialista Obrero Español) e institucionales principales vienen a legitimar un liderazgo institucional de naturaleza vertical en la que la administración central, por medio del Ministerio correspondiente, adquiere una posición privilegiada.

“... el liderazgo era un liderazgo prácticamente absoluto por parte del Ministerio. No tanto, también, por la personalidad de los ministros de turno, sino porque realmente había toda una serie de materias que eran las que tenían que ver la Conferencia Sectorial, en la que realmente, la única capacidad de iniciativa procedía del ministerio de turno" (E11).

Desde un punto de vista favorable a la realidad arriba dibujada uno de nuestros entrevistados se expresa de forma muy elocuente:

“... en temas como educación y sanidad, creo que se ha ido demasiado lejos en la transferencia de competencias a las comunidades autónomas. (...) sinceramente, creo que se nos ha ido la mano, en otros países no tienen tanto" (E03).

Los reglamentos de las conferencias analizadas no diseñaban un esquema concreto de relaciones entre sus miembros y podrían haberse abierto a formas alternativas a la que se ha impuesto.

De hecho, actores entrevistados en este trabajo, ex Consejeros del Partit del Socialistes de Catalunya, de Iniciativa per Catalunya y del gobierno del Partido Socialista de Euskadi, se muestran favorables a un sistema organizativo multilateral de tipo federal.

Uno de ellos esboza así su proyecto de conferencia:

“La Conferencia acaba siendo sólo, estrictamente, el contenedor formal de unas conversaciones entre partidos que de alguna manera se trasladan allí y... Bueno, nosotros nos resistíamos a ese papel: "No, no. Es la Conferencia Sectorial la que debe trabajar y dar un fondo a propuestas. Y establecer grupos de trabajo que avancen. $Y$ luego ya explicaremos a quien corresponda" (E04).

Otro de los entrevistados coincide en la propuesta:

"Pero si se quiere trabajar en serio hacia fórmulas verdaderas de cooperación (...) intentaría darle una posibilidad de trabajo autónomo, de trabajo propio, de iniciativa. (... ) Es decir, que la Conferencia tuviera algún elemento propio, de personalidad propia, que le diera sentido a esta cooperación." (E12).

Sin embargo las formas de entender las relaciones entre los actores territoriales que acabamos de describir no agotan las perspectivas de todos los entrevistados. Algunos de ellos optan por un esquema de relación bilateral entre la comunidad autónoma y la administración central que se situara fuera de la estructura organizativa de las Conferencias Sectoriales.

“...si todos tuviésemos el mismo nivel competencial, las mismas voluntades de autogobierno, los mismos problemas o atención a diferentes cosas, como los que tenemos lenguas propias, pero no, es que hay casos que no tienen esa situación. Por lo tanto a mí no me parece que las Conferencias Sectoriales sean el instrumento para una coordinación. Que haya que tener en un estado una determinada coordinación para fijar, no sé, los elementos básicos puros, todavía, pero yo vuelvo a plantear que nuestra referencia tiene que ser la bilateral" (E01).

En resumen, a través de sus declaraciones los entrevistados y entrevistadas reflejan otras opciones alternativas de cogobierno sobre las Conferencias Sectoriales, bien insistiendo en formas bilaterales bien en multilaterales. Frente a un órgano con un tipo de funcionamiento, calificado por gran parte de nuestros entrevistados y entrevistadas, de 
tipo jerárquico y vertical, se plantean dos opciones diferentes, la primera es partidaria de reconvertirlas en estructuras más horizontales, más federalizantes y la segunda muestra una opción alternativa a la Conferencia Sectorial, la potenciación en su lugar de los órganos de encuentro bilateral entre Comunidades Autónomas y Estado.

Tal y como se ha señalado anteriormente los informantes coinciden en el papel que el alineamiento partidista va a jugar en la toma de decisiones que se dan en las Conferencias Sectoriales. La alineación es uno de los factores que en mayor medida parecen explicar el funcionamiento y la adopción de resoluciones de las Conferencias analizadas. La razón de este hecho deriva, como se ha explicado en el punto anterior, de la percepción de una estructura territorial de relaciones entre la administración central y las autonomías de tipo jerárquico y vertical. En efecto, al debilitarse el eje de decisión territorial se refuerza la competitividad entre partidos y fundamentalmente entre el partido de gobierno y el principal partido de la oposición. En el relato de los presentes se observa la polarización que este hecho provoca en los plenarios de las Conferencias y expresa que los representantes de las Comunidades Autónomas intervienen muchas veces más en función de los intereses de su partido político que en función de los intereses de su comunidad.

Como podemos observar en las entrevistas sea cual sea la adscripción partidista de los consultados el grado de coincidencia en el diagnóstico es significativa.

"Antes de la reunión de la Conferencia Sectorial había un trabajo de cocina que no solamente era técnico sino que también era político. El ministerio de turno, lógicamente quería que sus propuestas saliesen adelante y para ello había una labor de comunicación previa con las Comunidades Autónomas, fundamentalmente (...) con las Comunidades Autónomas afines para tener el apoyo de las Comisiones, de las Conferencias, de las Consejerías propias.” (E11)

“El perfil ideológico es importante. De hecho, básicamente, las comunidades socialistas se encontraban antes para hablar de cómo afrontar el tema, las comunidades del PP también,... a la Conferencia se iba con la decisión tomada y, por tanto, en la Conferencia se escenificaba la discrepancia o el acuerdo." (E12).

"A lo que voy, imperaba la disciplina de partido versus una conversación que yo creo que debería haber sido cada vez más técnica”. (E14)

En los fragmentos que hemos seleccionado los informantes confirman el hecho del alineamiento en torno a los dos partidos mayoritarios e indican los efectos negativos que, en su opinión, provoca sobre el funcionamiento de las Conferencias; la politización general de los puntos del orden del día, la escenificación mediática del disenso y el vaciamiento de la dimensión de distribución territorial del poder político de las Conferencias.

\subsection{Liderazgo personal: habilidades sociales y perfil formativo}

Queremos diferenciar entre el liderazgo institucional otorgado por el ordenamiento jurídico y político analizado en el punto anterior y un liderazgo basado en habilidades sociales y capacidades profesionales de carácter más personal.

A lo largo de las entrevistas realizadas el ejercicio de un liderazgo individual basado en las habilidades sociales de los miembros de estos órganos, tales como el carácter dialogante, la capacidad de empatía o el carisma, son valoradas positivamente por los entrevistados como elementos favorecedores para el desarrollo de las Conferencias. En este punto es importante introducir una aclaración, para la mayoría de los interlocutores, este hecho, positivo, no indica que sean factores determinantes en el resultado final de las conferencias. Los rasgos ideológicos, la relación de fuerzas partidista que se da coyunturalmente, tienen un mayor peso en el proceso de toma de decisiones.

"Yo creo que es en todas las cosas, pero en la política una de las cosas que yo siempre he pensado que es un elemento fundamental, es el factor humano, la capacidad de relación o el tratar de entender. Si no hay una cierta empatía entre quienes están en un proceso de negociación, difícilmente se puede llegar a acuerdos, cuando hay muchas dificultades, pero se allana el camino, por llamarlo de alguna forma. (E01)

En el mismo sentido otro informante afirma:

"Ha habido momentos, aquí de nuevo entra el factor humano, el carácter que pueda tener el que más manda en la Conferencia Sectorial, es decir, el que la dirige, el Ministro o la Ministra. Si tú tienes 
un carácter dialogante y vas genuinamente a escuchar, incluso la discrepancia, para ver si la puedes integrar, entonces tiene mucho valor. Si lo que vas es a pasar un rodillo porque tienes mayoría absoluta... entonces, carece de valor" (E02).

Apuntando a lo que recogíamos en el párrafo anterior, podemos observar cómo el factor personal queda bajo la influencia de elementos de otro carácter que pueden ayudar a que tenga una mayor repercusión. Algunos de nuestros interlocutores nos indican que las habilidades sociales tienen mayor influencia en los órganos de coordinación de segundo nivel, tales como las comisiones, por tratarse de ámbitos más proclives al consenso.

“En la Comisión General un porcentaje importante. O sea, la habilidad, el buen trato, el buen rollo, la capacidad de convencimiento, todas estas cosas yo creo que son muy importantes. En ámbitos en donde el consenso es lo que estás buscando." (E12).

Los interlocutores convienen en que ámbitos más alejados de los escenarios mediáticos, habilitan una mayor influencia de los componentes del liderazgo de tipo personal que estamos analizando.

Finalmente, la relación profesional con la política sectorial en la que van a desarrollar su función es otro elemento que conforma la capacidad de liderazgo personal según las informaciones recogidas. La experiencia profesional, la trayectoria laboral, el conocimiento del sector son aspectos considerados importantes a la hora de evaluar las capacidades y el rendimiento de los miembros de las conferencias.

"A ver, ¿ahora qué hace falta, un hombre, una mujer? Venga, pues nombro a fulano de tal”, "Ya, pero no sabe nada de eso", "Ya, pero bueno y qué, pues ya se enterará". Pues no. Lo que pasa en sanidad es que no te enteras, porque es muy complejo... si tienes una curva de aprendizaje muy rápida puede que aprendas al tercer año y luego ya estás en elecciones, (...) esa incapacidad es muy importante porque el sector la nota enseguida. Y entonces la gente se distancia del tema”. (E14)

La cualificación profesional de los miembros de la Conferencia es presentada como elemento consustancial para el desarrollo del liderazgo personal y el funcionamiento adecuado de las Conferencias.

\section{CONCLUSIONES}

Las Conferencias Sectoriales aparecen en el sistema político administrativo español como el instrumento formal para canalizar las relaciones entre el Estado y las Comunidades Autónomas. Su estudio muestra, a primera vista, un universo diverso y unos orígenes y trayectorias con ritmos distintos; sin embargo, cuando se analizan las dinámicas de funcionamiento en cuanto a sus funciones, composición y asistencia, convocatoria y orden del día, órganos de preparación y apoyo y la toma de decisiones, se pueden apreciar una serie de aspectos compartidos, aunque no coincidentes, entre las tres Conferencias Sectoriales analizadas y sobre los cuales las percepciones de nuestros entrevistados aportan información y crítica sobre la dinámica operativa de éstas.

Desde el punto de vista del funcionamiento, la percepción del rendimiento de estos órganos respecto a la capacidad de cogobierno es baja, tal y como expresan nuestros entrevistados y entrevistadas, dependiendo, en gran medida, de factores de carácter político y humano que llegan a relativizar su potencial como verdaderos instrumentos para la canalización de la cooperación intergubernamental.

Por otra parte, hemos visto también cómo el impacto del factor humano, en su expresión de liderazgo personal, adquiere mayor importancia en los órganos de segundo nivel, mientras que el grado de institucionalización de las conferencias les hace inmunes a las relaciones personales en lo que toca a los alineamientos internos y la toma de decisiones. Estas siguen procedimientos pautados independientemente del perfil de las personas participantes.

En definitiva, la historia de las Conferencias Sectoriales es sintomática de las principales carencias del modelo territorial español. La relativa ausencia de actores que apuesten decididamente por la cooperación interterritorial vacía de contenido estas instituciones, redundando en la falta de gobierno compartido propia del modelo autonómico español. Un gobierno compartido que debería de ser, no lo olvidemos, la otra cara de la descentralización para avanzar a un modelo propiamente federal.

\section{REFERENCIAS BIBLIOGRÁFICAS Y DOCUMENTALES}

Agranoff, R. (2006), Federal asymmetry and intergovernmental relations in Spain. Asymmetry Series edn. Montreal: Queen's University.

Aja, E. (2014), Estado autonómico y reforma federal. Madrid: Alianza. 
Arbós, X., Colino, C., Garcia, M.J. y Parrado, S. (2009), Las relaciones intergubernamentales en el Estado autonómico. La posición de los actores. Barcelona: Institut d’Estudis Autonómics, Generalitat de Catalunya.

Colino Camara, C. (2014): "Relaciones Intergubernamentales en el sistema federal español: en búsqueda de un modelo" En López Basaguren, A. y L. Escajedo San Epifanio (Coord.) Los caminos del federalismo y los horizontes del Estado Autonómico. Ed. IVAP, Bilbao.

Colino, C. Y Parrado, S. (2009), “Análisis de la práctica y la dinámica de los procesos formales e informales de las relaciones intergubernamentales”, en X. Arbós et al, Las relaciones intergubernamentales en el Estado autonómico. La posición de los actores. Barcelona: Institut d’Estudis Autonómics, Generalitat de Catalunya: 135 y ss.

Duque Villanueva, J.C. (2007), “Las Conferencias Sectoriales”, Revista Española de Derecho Constitucional, n. ${ }^{\circ} 27$.

Lagos, M.G., Iglesias, A. y Álamo, R. (2010), "Solidaridad y financiación autonómica”, Estudios de economía aplicada, 28(1): 103-122.

Linz, J.J., (1997), “Democracy, Multinationalism, and Federalism”. Estudios / Working Papers (Centro de Estudios Avanzados en Ciencias Sociales), (103).

Máiz, R., Beramendi, P. y Grau, M. (2002), “La federalización del Estado de las Autonomías: evolución y déficit institucionales" en J. Subirats y R. Gallego (coords.), Veinte años de autonomías en España: leyes, políticas públicas, instituciones y opinión pública. Madrid: CIS.

Marks, G., Hooghe, L. y Schakel, A. (2008), “Measuring Regional Authority”, Regional \& Federal Studies, 18 (2): 111121. DOI:10.1080/13597560801979464.

Mendoza, X. (1990): “Técnicas gerenciales y modernización de la administración pública en España”, Documentación Administrativa, n. ${ }^{\circ}$ 223. INAP, Madrid.

Ministerio de Hacienda y Administraciones Públicas (MINHAP), Informes sobre la actividad de las Conferencias Sectoriales (años 2009, 2010, 2011 y 2012). En línea: http://seap.minhap.gob.es/es/areas/politica_autonomica/ coop_autonomica/Conf_Sectoriales/Documentacion.html (última consulta: noviembre 2014)

Ministerio de Hacienda y Administraciones Públicas (MINHAP): Informes sobre la actividad de las Conferencias Sectoriales (años 2002 y 2007). En línea: http://www.seap.minhap.gob.es/dms/es/publicaciones/centro_de publicaciones_de_la_sgt/Periodicas/parrafo/0111110/text_es_files/Publicacion.pdf (última consulta: noviembre de 2014).

Mondragón, J, Elizondo A., De La Peña A., Juaristi F. y Mokoroa J.L. (2015): Análisis de las conferencias sectoriales (2001-2012): valores y percepciones de los agentes políticos y técnicos y dinámica de funcionamiento. INAP, Madrid.

Moreno, L. (1997): La federalización de España. Poder político y territorio. Ed. Siglo XXI, Madrid.

Peña Díez, J.F. (2010), “De una Administración prestacional a una relacional en el estado de las autonomías. Luces y sombras de una experiencia inédita”, Documentación administrativa, 286: 59-78.

Pérez García, F., (2002), “La financiación del Estado autonómico: una lectura de veinte años de descentralización” en A. Cuco, J. Romero y J. Farinos, ed., La organización territorial del Estado, España en Europa: un análisis comparado. Universitat de València: 41-66.

Romero González, J. (2005), “El Gobierno del territorio en España. Balance de iniciativas de coordinación y cooperación territorial”, Boletín de la AGE, 39: 59-86.

Ruiz González, J.G. (2012): “La cooperación intergubernamental en el Estado autonómico”: Situación y perspectivas", Revista d'Estudis Autonòmics i Federals, 15: 288-327.

Ruiz González, J.G. (2013), Logros y retos de las Conferencias Intergubernamentales en España. Working Paper GIGAPP.

Tajadura Tejada, J. (2010), "Federalismo cooperativo y Conferencias Sectoriales: marco normativo y propuestas de reforma”, Revista jurídica de Navarra, 49: 137-181.

Vega García, A. (2014), “El principio constitucional de solidaridad interterritorial en España y en Alemania: Aplicación y límites”, Revista d'estudis autonòmics i federals, 20: 214-277.

Wright, D. S. (1997), Para entender las relaciones intergubernamentales. México: Fondo de Cultura Económica. 
ANEXO I. FICHA TÉCNICA DE LAS ENTREVISTAS EN PROFUNDIDAD

\begin{tabular}{|c|l|l|c|l|c|}
\hline $\begin{array}{c}\text { Entrevista } \\
\text { n. }\end{array}$ & \multicolumn{1}{|c|}{ Ámbito } & $\begin{array}{c}\text { Comunidad Autónoma/ } \\
\text { Ministerio }\end{array}$ & $\begin{array}{c}\text { Partido } \\
\text { Político }\end{array}$ & $\begin{array}{c}\text { Fecha } \\
\text { realización } \\
\text { entrevista }\end{array}$ \\
\hline 01 & Educación & País Vasco & EA & Consejero/a & 19-05-2014 \\
\hline 02 & Educación & País Vasco & PSE & Consejero/a & $10-06-2014$ \\
\hline 03 & Educación & Madrid & PP & Consejero/a & $22-04-2014$ \\
\hline 04 & Educación & Cataluña & PSC & Consejero/a & $25-04-2014$ \\
\hline 05 & Sanidad & Cataluña & PSC & Consejero/a & 08-05-2014 \\
\hline 06 & $\begin{array}{l}\text { Medio } \\
\text { Ambiente }\end{array}$ & $\begin{array}{l}\text { Ministerio de Agricultura, } \\
\text { Alimentación y Medio }\end{array}$ & - & $\begin{array}{l}\text { Secretario de la Comisión } \\
\text { de Medio Ambiente }\end{array}$ & $22-06-2014$ \\
\hline 7 & $\begin{array}{l}\text { Medio } \\
\text { ambiente }\end{array}$ & $\begin{array}{l}\text { Ministerio de Agricultura, } \\
\text { Alimentación y Medio } \\
\text { Ambiente }\end{array}$ & - & $\begin{array}{l}\text { Secretaria de la } \\
\text { Conferencia Sectorial de } \\
\text { Medio Ambiente }\end{array}$ & $16-05-2014$ \\
\hline 08 & Sanidad & Cataluña & CDC & Consejero/a & $17-06-2014$ \\
\hline 09 & $\begin{array}{l}\text { Medio } \\
\text { Ambiente }\end{array}$ & Cataluña & ICV & Consejero/a & $20-06-2014$ \\
\hline 10 & $\begin{array}{l}\text { Medio } \\
\text { Ambiente }\end{array}$ & País Vasco & EA & Consejero/a & $26-06-2014$ \\
\hline 11 & $\begin{array}{l}\text { Medio } \\
\text { Ambiente }\end{array}$ & Madrid & PP & Consejero/a & $16-05-2014$ \\
\hline 12 & Educación & Cataluña & PSC & Director General & $18-07-2014$ \\
\hline 13 & $\begin{array}{l}\text { Cooperación } \\
\text { Autonómica }\end{array}$ & $\begin{array}{l}\text { Ministerio de Hacienda y } \\
\text { Administraciones públicas }\end{array}$ & - & $\begin{array}{l}\text { Subdirector General de } \\
\text { Cooperación Autonómica }\end{array}$ & $12-10-2014$ \\
\hline 14 & Sanidad & País Vasco & PSE & Consejero/a & $24-07-2014$ \\
\hline 15 & $\begin{array}{l}\text { Cooperación } \\
\text { autonómica }\end{array}$ & $\begin{array}{l}\text { Ministerio de Hacienda y } \\
\text { Administraciones públicas }\end{array}$ & - & $\begin{array}{l}\text { Subdirectora General } \\
\text { Adjunta de Cooperación } \\
\text { Autonómica }\end{array}$ & $12-10-2014$ \\
\hline ambiente & País Vasco & Viceconsejero & $22-05-2014$ \\
\hline 16 & Medio & & \\
\hline
\end{tabular}

